\title{
Ruthenium Bipyridine-Containing Polymers and Block Copolymers via Ring-Opening Metathesis Polymerization
}

\author{
Bingzhi Chen, Hanadi F. Sleiman \\ Department of Chemistry, McGill University, 801 Sherbrooke St. W., Montreal, QC, \\ H3A 2K6, Canada
}

(1) HR-FAB-MS of compund 1 and HR-ESI-MS of monomer 3.

(2) ${ }^{1} \mathrm{H}$ NMR and ${ }^{13} \mathrm{C}$ NMR of compund $\mathbf{1}$, monomer $\mathbf{3}$, homopolymer, copolymer $\mathbf{6}$ and ${ }^{1} \mathrm{H}$ NMR copolymer 6 in $\mathrm{CD}_{3} \mathrm{CN} / \mathrm{d}_{8}$-toluene before and after formation of micelle.

(3) CV of monomer 3, homopolymer $\mathbf{4}$ and copolymer 6.

(4) First-Order kinetics of the ROMP of 5 with catalyst 7. 


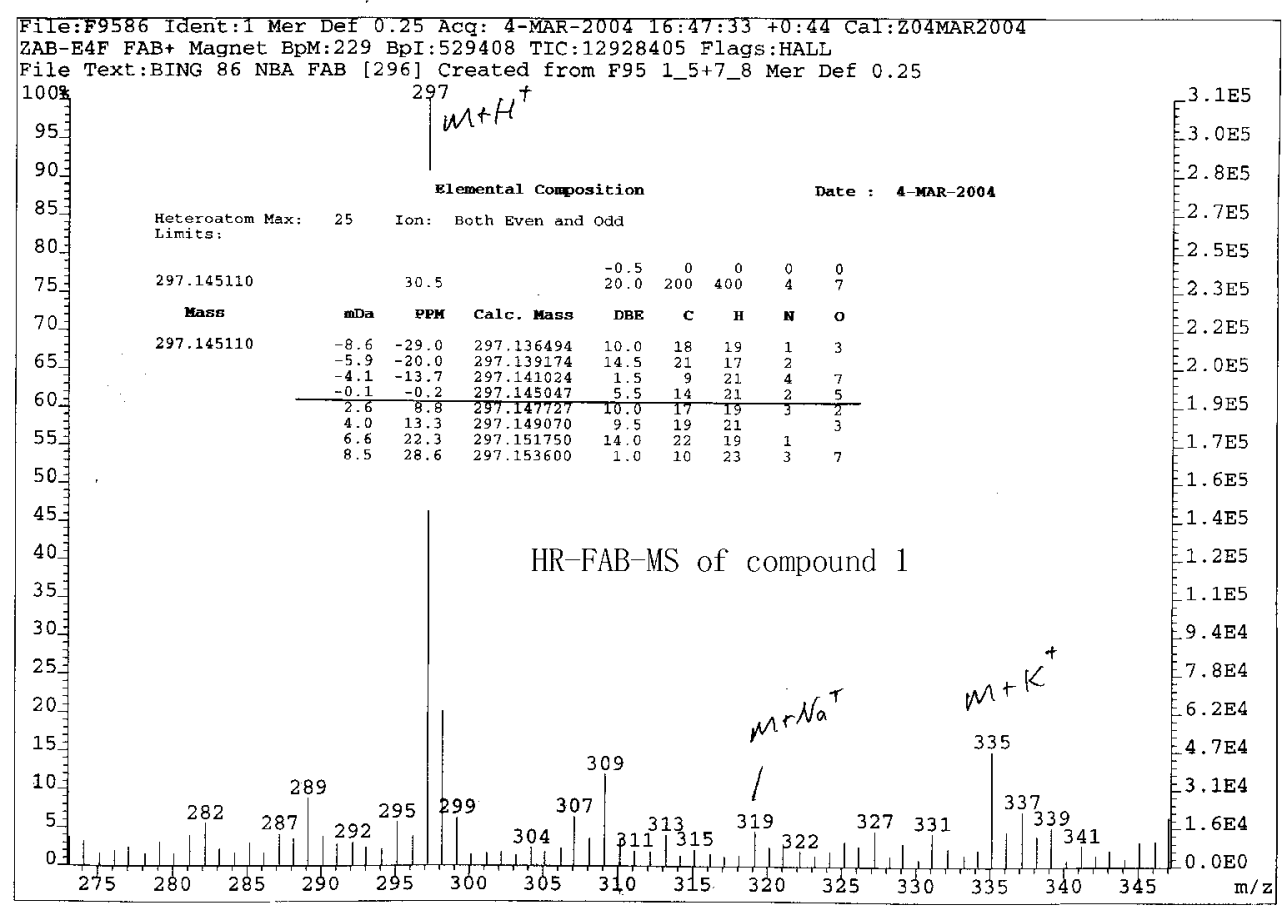

IonSpec HiResESI

File: FTMSA30 SLESEANN BiNg-96(1051) MS CAL.trans

$\begin{array}{lll}\text { Mode: Positive } & \text { Dale: } & \text { 06-MAR-2004 } \\ \text { Scans: } 1 & \text { Time: } & 10: 59: 55\end{array}$

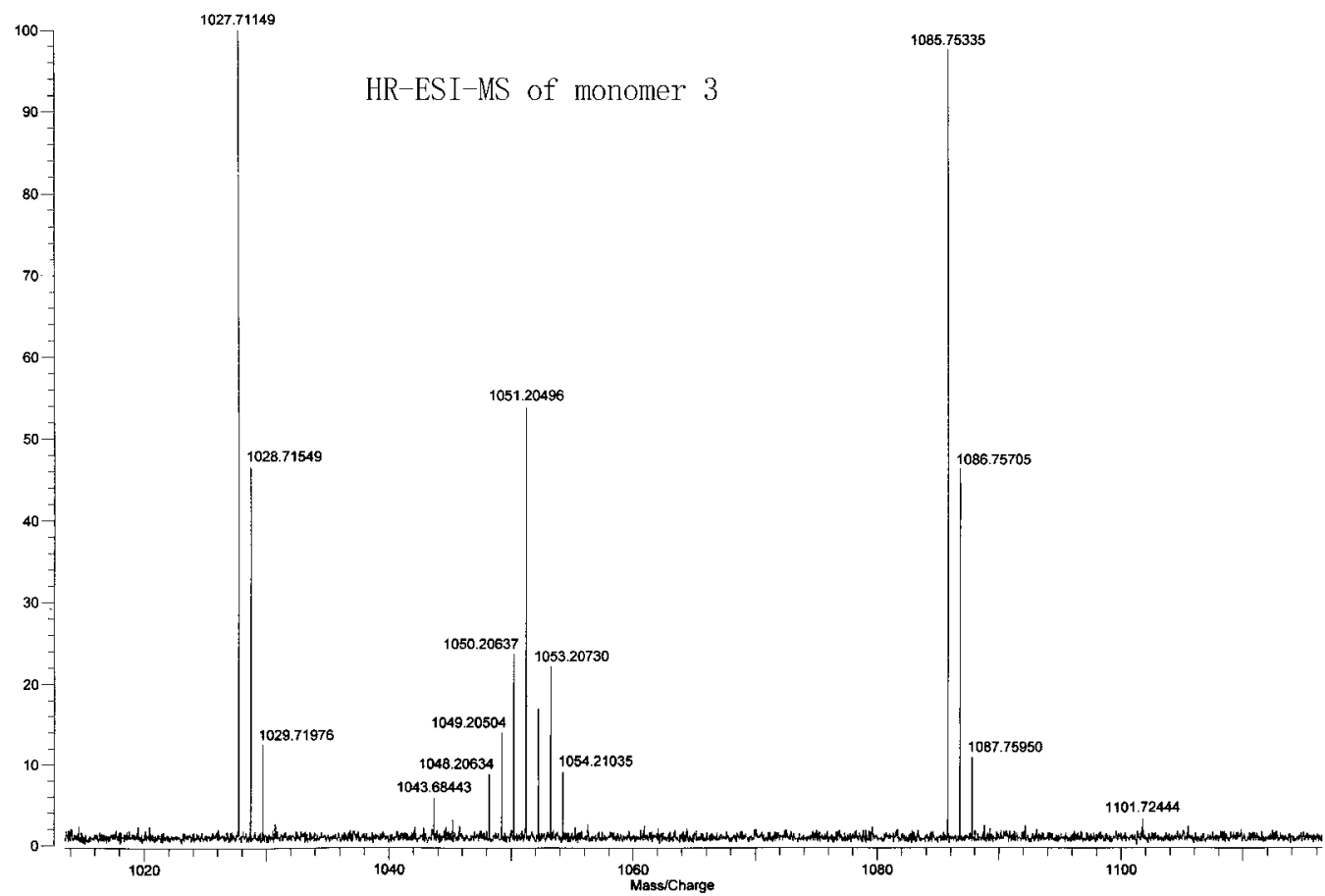


1HNMR of compound 1 in $\mathrm{CD} 3 \mathrm{C} 1$

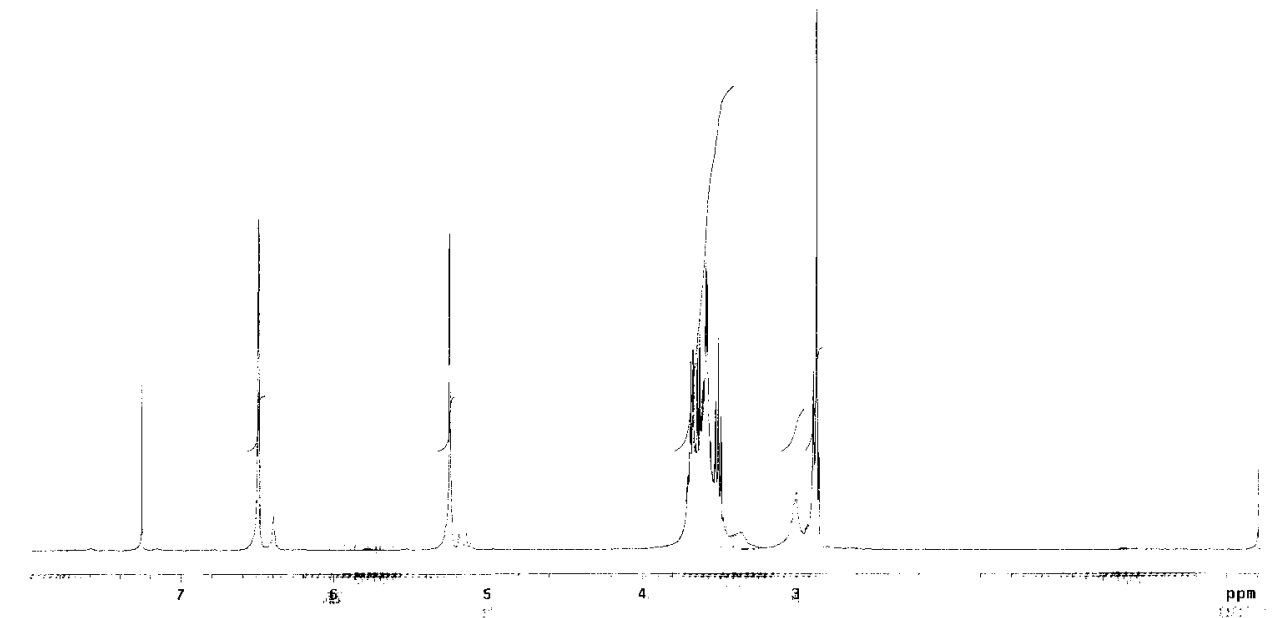

1HNMR of monomer 3

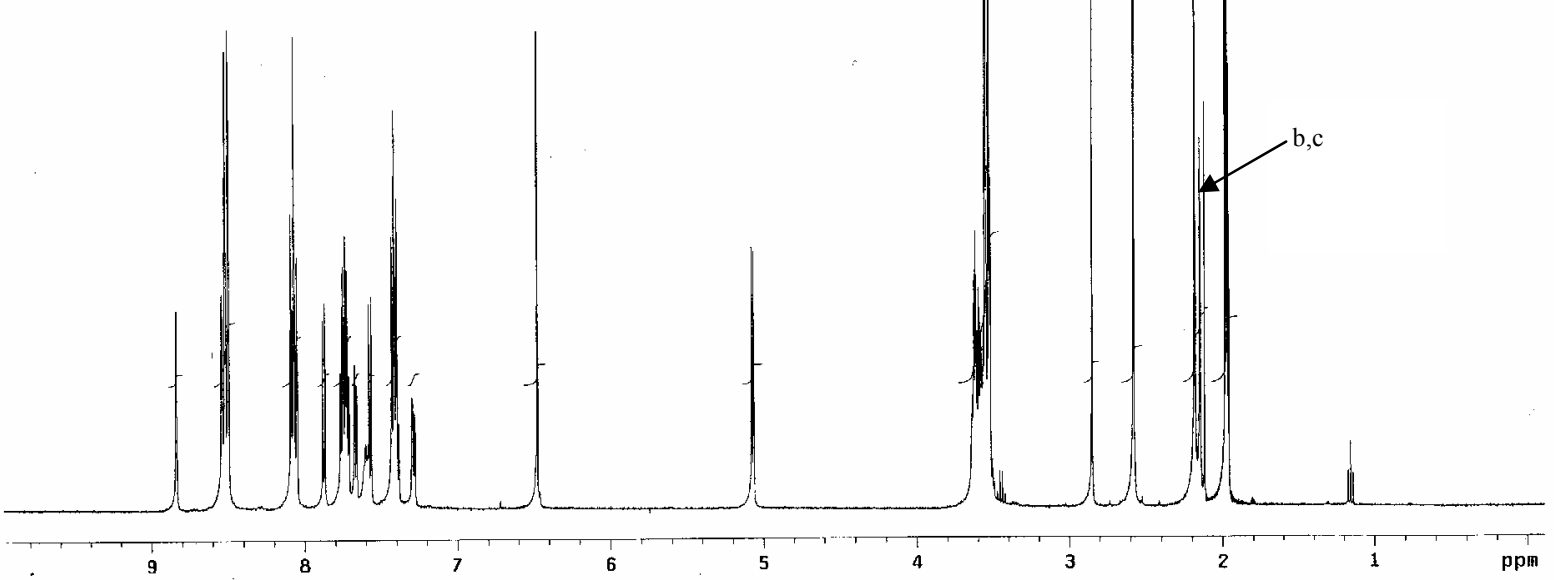

a: $\mathrm{CH}_{3} \mathrm{CN}$; b: acetone impurity; c: impurity in the $\mathrm{CD}_{3} \mathrm{CN}$ solvent; d: water 

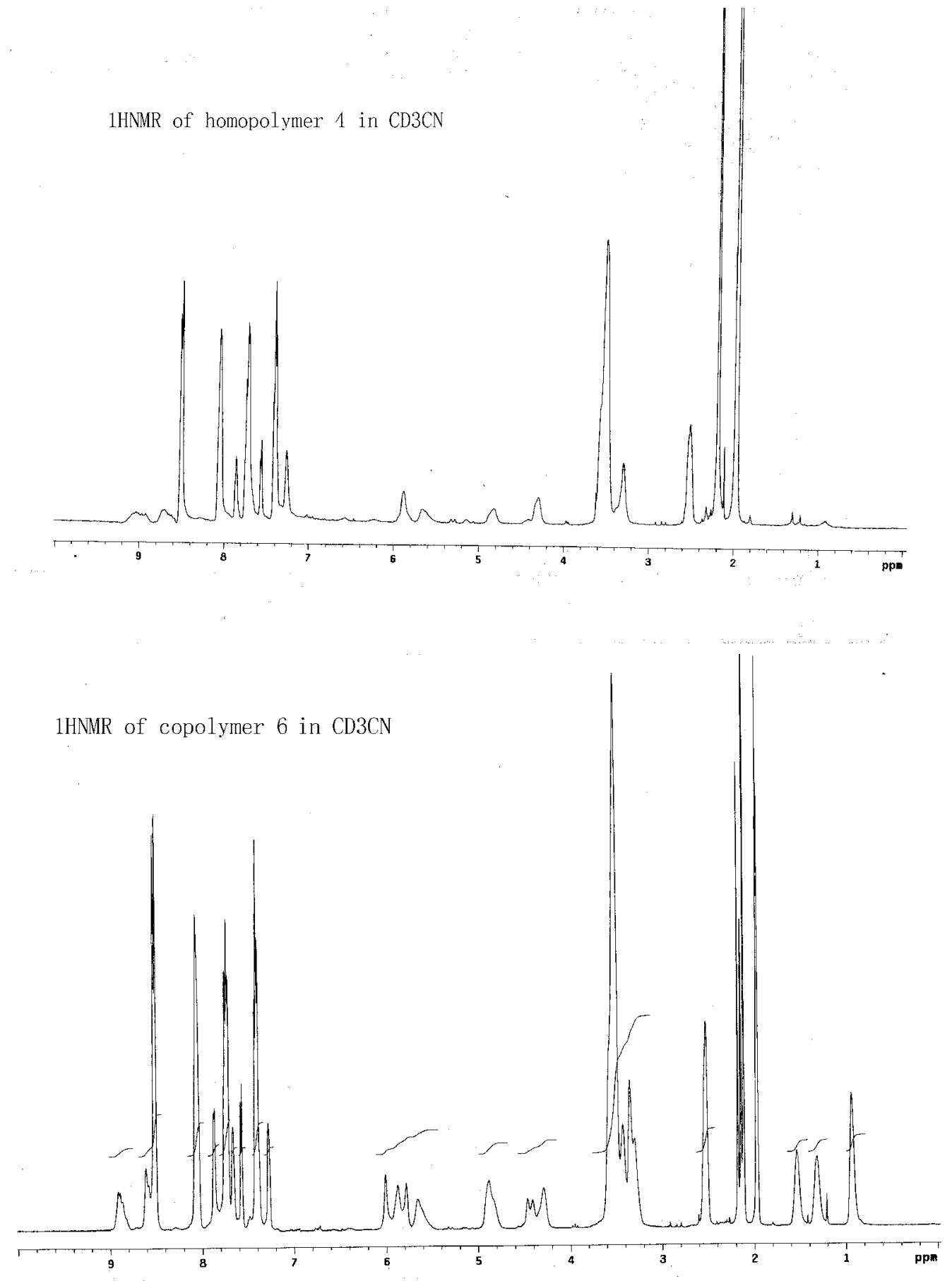
13CNMR of compund 1 in CD3C1

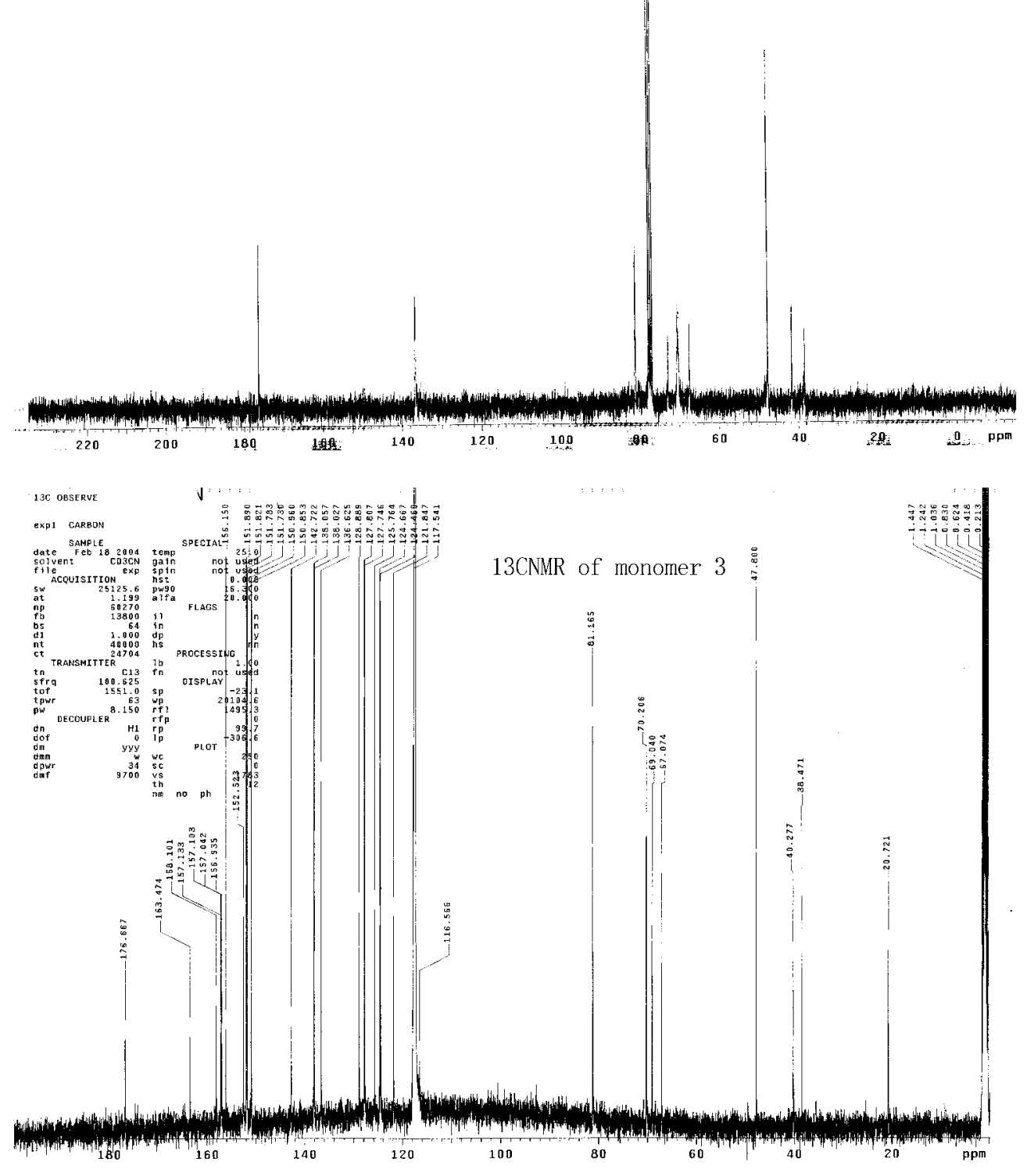



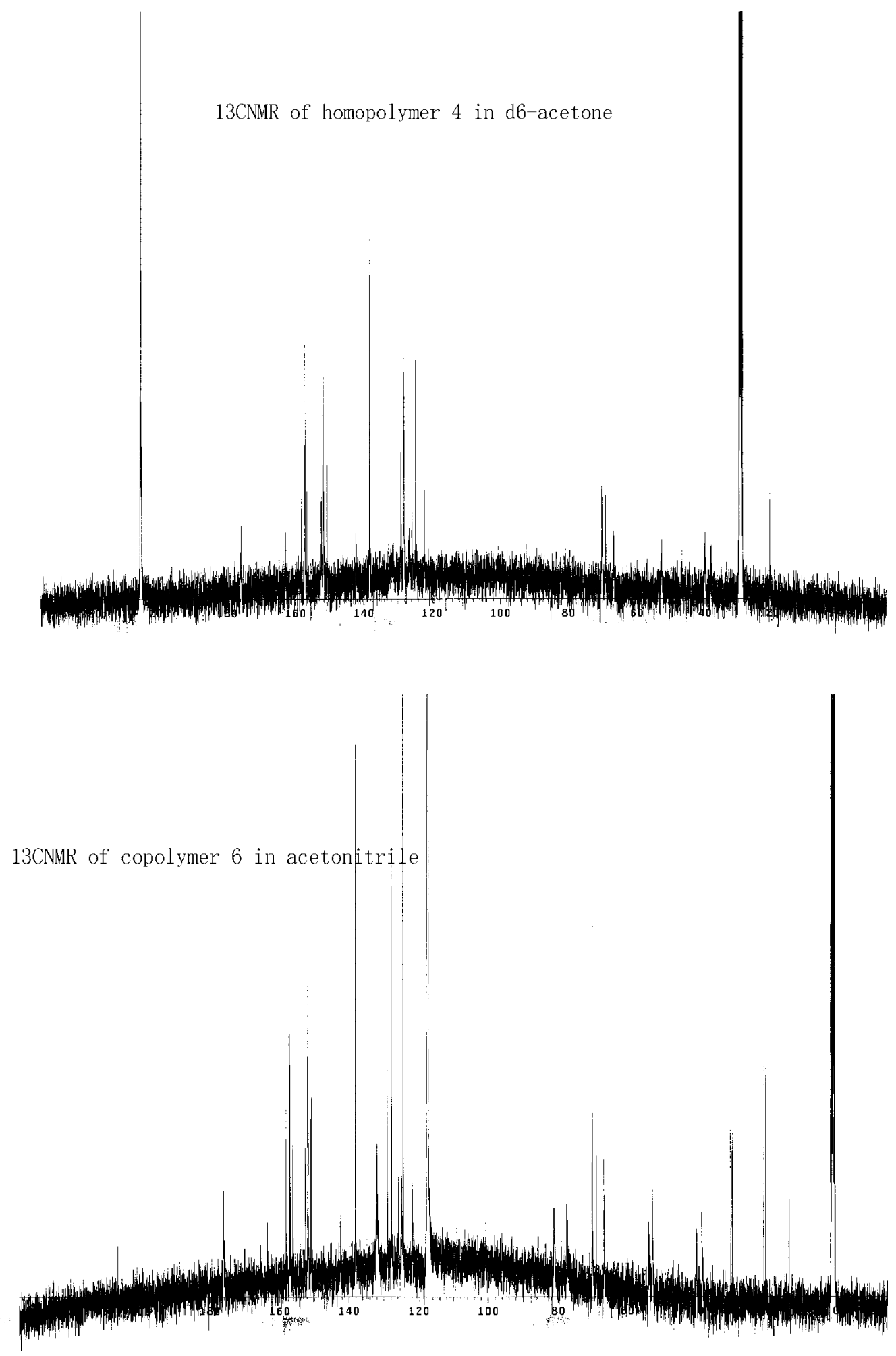


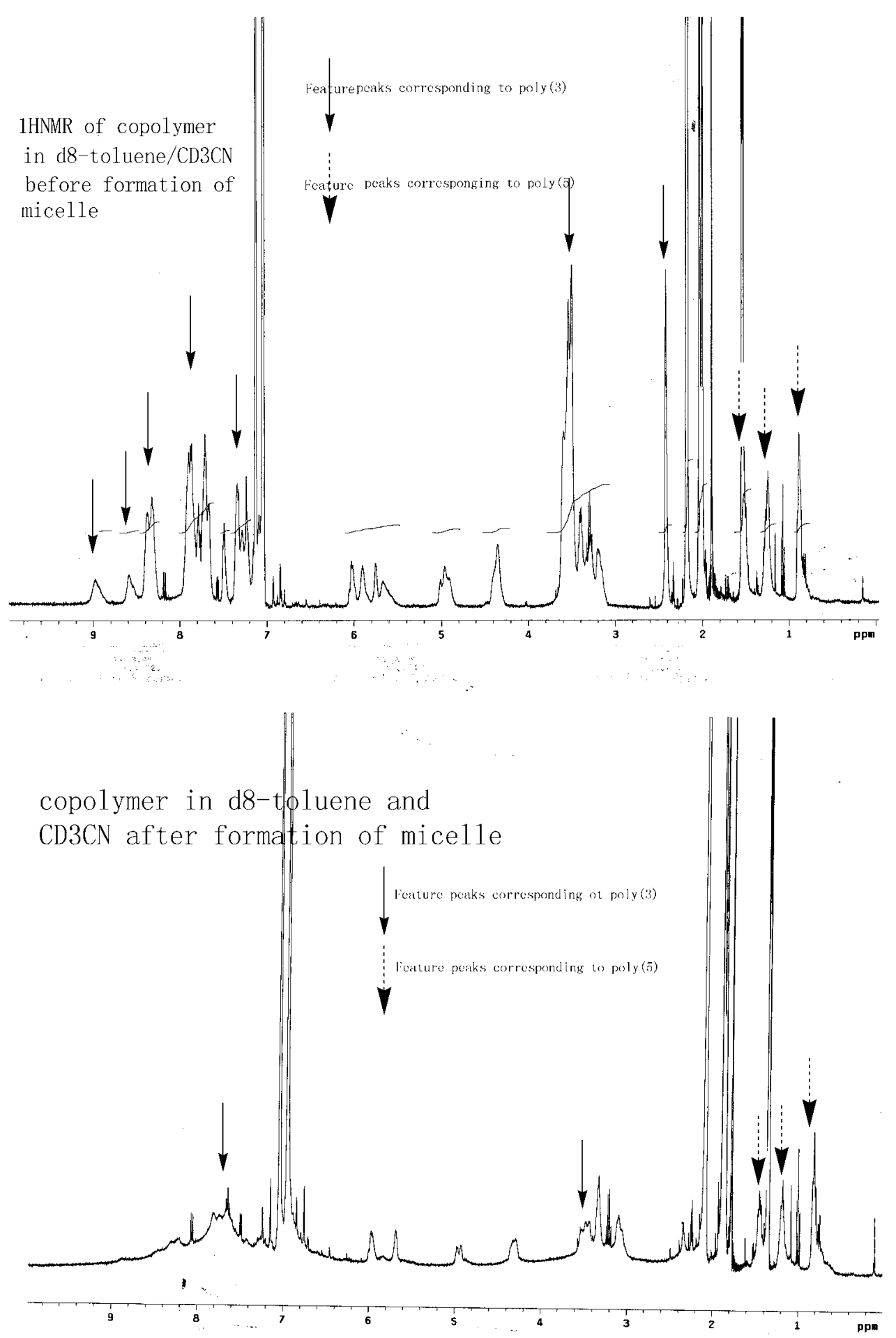



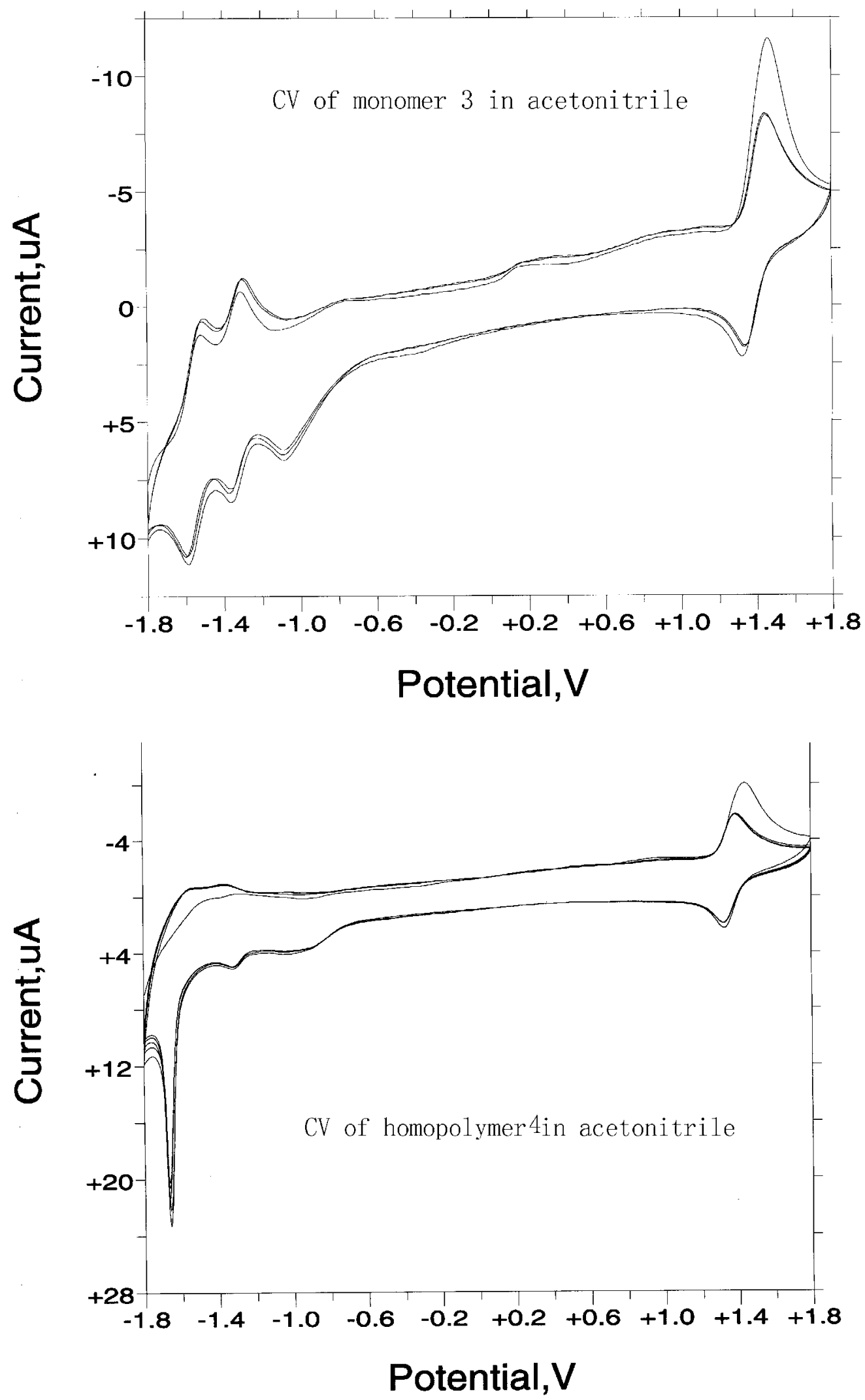


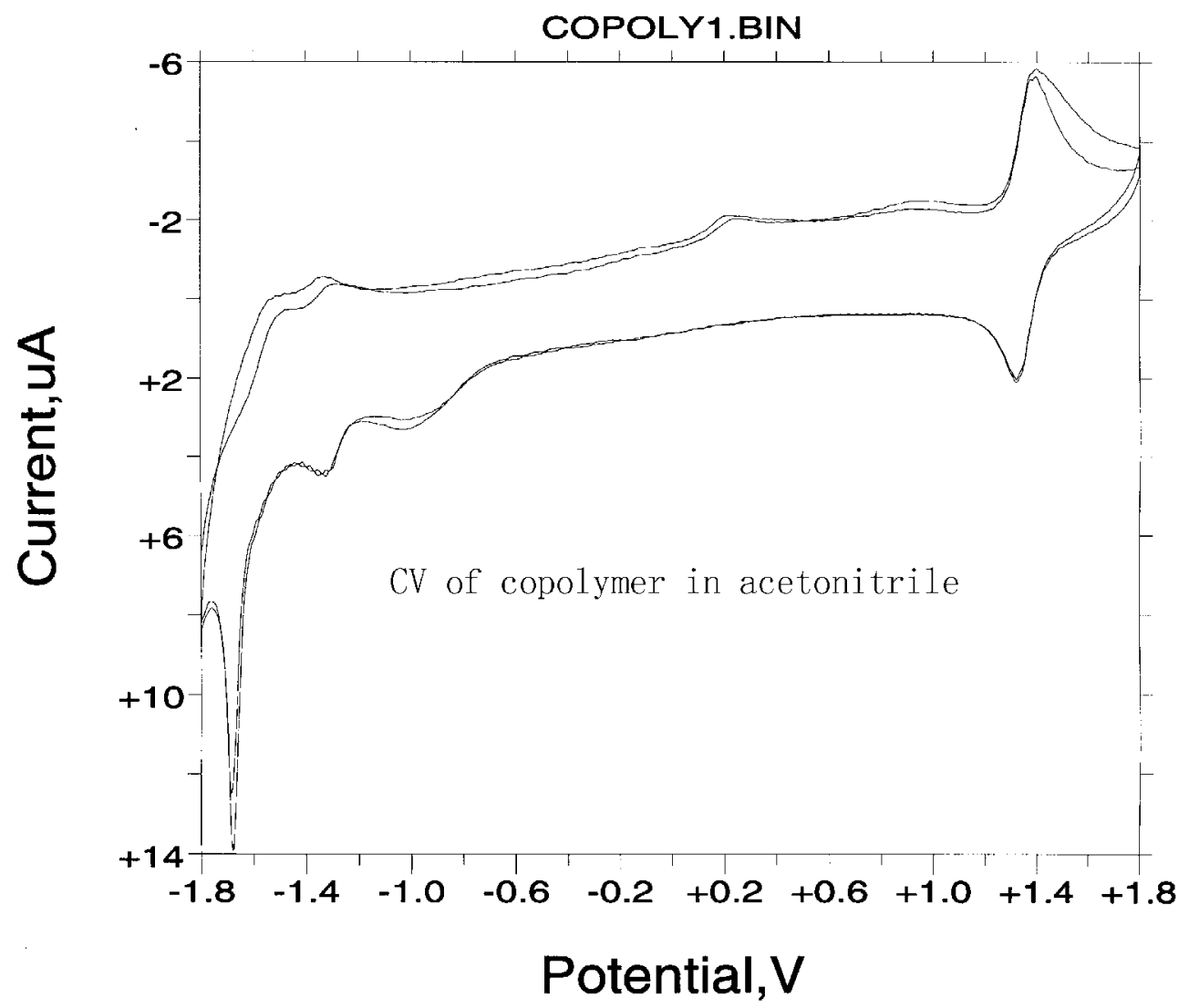




\section{First-Order kinetics of the ROMP of 5 with catalyst 7.}

The living nature of the ROMP reaction of monomer 5 with catalyst 7, was established by monitoring the polymerization with ${ }^{1} \mathrm{H} \mathrm{NMR}$ in $\mathrm{d}_{6}$-acetone at $-20^{\circ} \mathrm{C}$ under inert atmosphere. Analysis of the spectra revealed a clear linear dependence of the monomer conversion on reaction time, (see below) providing evidence for the living character of this polymerization.

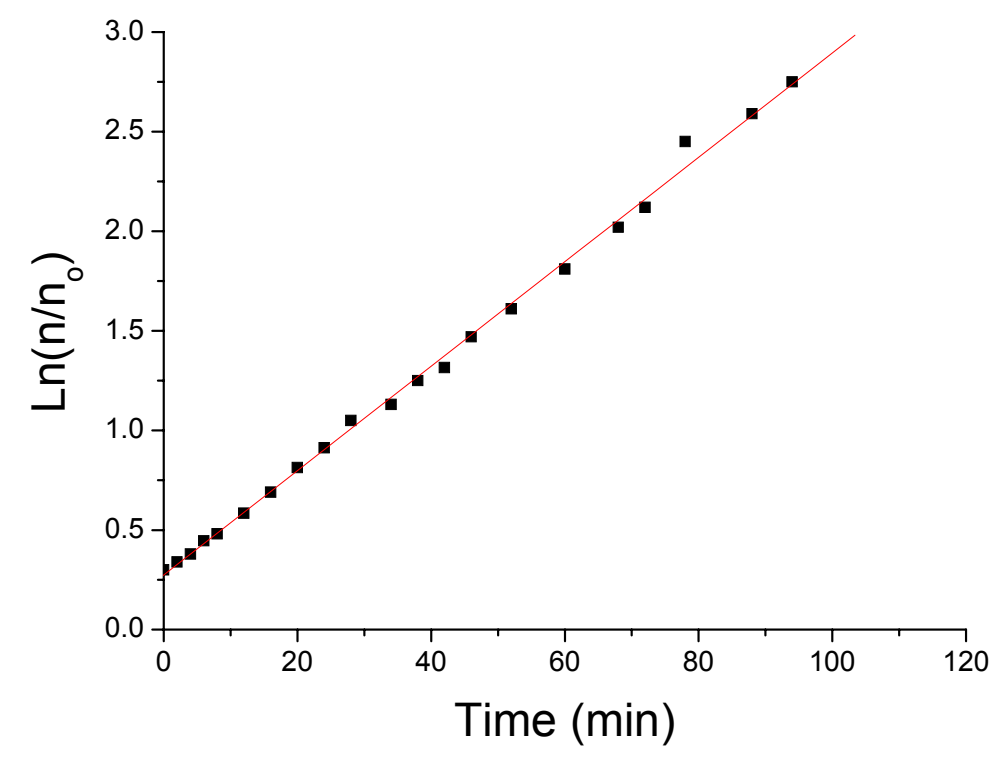

$\mathrm{n}={ }^{1} \mathrm{H}$ NMR integration of the remaining monomer concentration at time $\mathrm{t} ; \mathrm{n}_{0}={ }^{1} \mathrm{H}$ NMR integration of the initial monomer concentration. Linear regression analysis $(\mathrm{R}=0.99872)$. The $\mathrm{n} / \mathrm{n}_{0}$ values were obtained by integration of the olefin peaks of the monomer/(monomer plus polymer). The intercept of the graph above is not zero, because the NMR experiment started at a time later than the actual start of the reaction. 